west, accompanied with much lightning and thunder. Immediately hailstones became mingled with the rain, attention being drawn to their advent by the sharpness with which they struck on the shingled roofs. The west door of the laboratory being open to the air, the hail came in freely, nearly covering the floor for more than 12 feet. The hailstones were of clear ice, inclosing a few bubbles of air, varying from mere points to bubbles of the size of a split pea. The shape of the stones
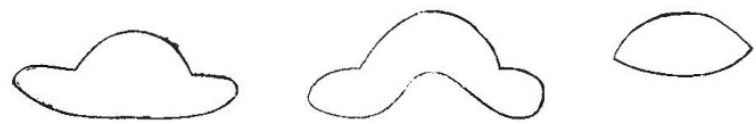

was singular. Suppose a shallow and very thick saucer to have a shallow cup, without a handle, inserted in it, and you will have a good idea of the form of the hailstones when unbroken. Many had more or less lost the "saucer" by violence, while some were entirely without it, presenting the appearance of a double convex lens with faces of different curvature.

By actual measurement the hailstones were found to vary from one-quarter to three-quarters of an inch in diameter, and from one-eighth to one-quarter of an inch in thickness at the thickes part. I observed that in very many of the larger stones the air. bubbles could move about, showing the interior to be still liquid ; as melting proceeded the bottom of the "saucer" would suddenly give way and become concave. The storm lasted about I 5 or 20 minutes, hail falling for the greater part of the time. The hail which fell on grass remained unmelted for ten or fifteen minures after the rain ceased. The fall of hail was very local, none falling at my house a mile away. I am informed that hail last fell in Kingston in 1839 .

Government Laboratory, May Iz. JAMES JOHN BOWREy.

\section{Singular Nesting-place of Linnets}

IT may be interesting to some of your readers to know of the recurrence of a strange freak on the part of a pair of linnets. Last year they selected, as the scene of their nest-building and other parental operations, the interior of a Maltese water-bottle, hung against a brick wall, at the back of the house of Capt. G. Wood, and in a sort of half yard, half garden. The bottle is of porous ware, Io inches high, 7 inches wide at its broadest part, which is mid-way between the bottom of the neck and the base, and having an upright constricted neck 4 inches long and only $\mathbf{I} \frac{1}{4}$ inches in diameter on the inside. In this singular receptacle the birds contentedly built, laid their eggs, and successfully reared their brood.

This year, strange to say, the same pair, or one identically like them, have returned to the old haunt, deftly repaired and slightly added to the old nest, laid their eggs, and now have a vigorous progeny of five or six unfledged youngsters.

How the birds cane, in the first instance, to select such a shelter, seeing that they could only pass in or out with folded wings, and by a sort of dart, and that to enter the neck from within in this way must have been a task of con:iderable skil and no little difficulty, is a mystery ; but that they should have retained such a happy memory of their first sojourn as to lead them to return to their old quarters, is more interesting still.

3 Waterloo Place, North Shields, June 2.

H. Vian-Williams,

\section{A Brilliant Meteor.}

YESTERDAY I saw a very brilliant meteor with train, resembling a firework in shape, colour, and other fentures. It was coming from Ursa Major, and vanished midway between a Lyra and $\delta$ Cygni. Motion very slow; $2 \mathrm{rh}$. $19 \mathrm{~m}$. mean Turin time. Turin, June i I. F. PORRO.

\section{ELECTRICITY AT OXFORD.}

$\mathrm{T}$ is with very great regret that we learn that the study of natural science in the University of Oxford received last week a blow which is all the more to be deplored in that it was, in part at all events, delivered by those from whom such an onslaught was least to have been expected. Professed hostility or indifference to the great scientific movement of the day, injudicious economy, - these are obstacles which promoters of that movement must be prepared to face, and will in the long run overcome. It is not, however, to be expected that progress will be made if each forward step is checked by those who have themselves enlisted on the side of science.

The cardinal point which the University had to decide was whether it should or should not provide itself with a laboratory for the development of the teaching of electricity. The Clarendon Laboratory was, we believe, the first building in this country which was planned and erected for the study of experimental physics alone. It was designed about twenty years ago by Prof. Clifton, and, if we except the provision made for electricity, nothing better or more complete is to be found within the four seas.

Rooms were, it is true, originally set apart as electrical laboratories. The rapid growth of the science would have sufficed to render them inadequate now, but we gather from a statement circulated by Prof. Clifton that other causes have combined to strengthen the case for an extension of the building.

Optics has been a favourite subject among students of physics at Oxford, and optical apparatus now occupies the space intended for electrical instruments. Thus it has come to pass that "the importart branches of electricity and magnetism are," in the words of the Professor, "necessarily excluded from the practical course."

In consequence of this unsatisfactory condition of affairs, Prof. Clifton has for some years lectured almost exclusively on electricity, and has been compelled to discuss methods of manipulation and details as to instruments which are usually mastered in a laboratory. The Lee's Reader in Physics, Mr. R. Baynes, has also established a practical course on electrical measurements, in Christ Church. Although the work he has thus done is excellent, we believe that it is not contended that Christ Church is in a position to make a permanent provision for instruction in electricity on a scale adequate to the requirements of the University.

For some time past, therefore, the University has been urged to add a wing for electrical work to the Clarendon Laboratory.

The necessity of providing for other University requirements has caused a long delay, but at length the turn of physics seemed to have come. Plans prepared by Prof. Clifton were submitted to the Hebdomadal Council. Mr. Henry Wilde, F.R.S., generously promised a gas-engine, dynamos, and an electric lamp. The Delegates of the Museum (who superintend the laboratories of the University), the Curators of the Chest (who have charge of its financial affairs), approved the scheme. It was adopted by the Council, and nothing remained but for the graduates in Convocation assembled to give their assent.

At the last moment, however, unexpected opposition arose. Balliol and Trinity Colleges have for some years combined their provision for the teaching of natural science, and the President of Trinity, acting for these Colleges, issued a pamphlet hostile to the grant for the proposed new laboratory. This step was taken on two grounds, both of which appear to us mistaken.

In the statement above referred to, Prof. Clifton had mentioned as an advantage incidental to the erection of the new laboratory that he would be able to abandon the lecture course of electrical demonstrations, as the instruction given in them would be better provided for in laboratory work. He proposed to substitute a general course on physics, addressed not only to the comparatively few students who aim at high honours in that subject, but to the larger body who enter for the first or preliminary stage of the honour examination. To this 